\title{
A PSICOLOGIA NA AVIAÇÃO: ATUAÇÃO DO PSICÓLOGO APÓS OCORRÊNCIA DE ACIDENTE AERONÁUTICO
}

\author{
PSYCHOLOGY IN AVIATION: PSYCHOLOGIST'S PERFORMANCE AFTER \\ AERONAUTICAL ACCIDENT
}

Ketllen dos Santos Oliveira ${ }^{\mathrm{I}}$

Fernanda Maria de Lira Correia ${ }^{2}$

RESUMO; Com o crescimento da demanda de passageiros para o transporte aéreo, a segurança da aviação civil tem evoluído cada vez mais através de uma estrita regulamentação, uso de alta tecnologia e recursos humanos qualificados, visando desenvolver ações preventivas capazes de identificar as vulnerabilidades que possam afetar o setor aéreo, no entanto, acidentes aeronáuticos continuam sendo uma realidade. Dessa forma, o presente artigo teve como objetivo geral apontar a atuação do psicólogo frente a situações de crise em contextos de acidentes aeronáuticos. Tratou-se de uma pesquisa bibliográfica e de abordagem qualitativa. Observou-se que a área da psicologia da aviação pauta sua atuação desde a prevenção até a ocorrência de acidentes, dialogando diretamente com a gestão integral de riscos e desastres proposta pelo Conselho Federal de Psicologia. Nesse sentido, considerando a ocorrência de um acidente aeronáutico, os grupos mais afetados tendem a ser: sobreviventes; membros de equipe de resgate e bombeiros; familiares e amigos; testemunhas e tripulantes, podendo ocasionar uma situação de crise e impactos psicológicos transitórios ou prolongados, que podem incluir transtornos psicológicos e mudanças significativas na vida. Nessa perspectiva, a intervenção em crise visa auxiliar a pessoa acometida pela busca por estratégias adaptativas à sua nova situação e também na prevenção do Transtorno de Estresse Pós-Traumático. Concluiu-se que para atuar no gerenciamento da crise após o acidente, é necessário prestar um suporte humanizado aos afetados, além da utilização de técnicas como os Primeiros Socorros Psicológicos ao longo do primeiro mês após o desastre.

Palavras-chave: Psicologia. Aviação. Acidentes Aeronáuticos. Desastres. Intervenção em Crise.

\footnotetext{
1 Psicóloga, Bacharel em psicologia pelo Centro Universitário Estácio do Recife. E-mail: ketllenolir4@gmail.com

2 Psicóloga, Docente do curso de psicologia do Centro Universitário Estácio do Recife. Email: correia.fernanda@estacio.br.
} 
ABSTRACT: With the growth in passenger demand for air transport, civil aviation security has evolved more and more through strict regulation, the use of high technology and qualified human resources, aiming to develop preventive actions capable of identifying the vulnerabilities that may affect the aviation sector, however, aviation accidents remain a reality. Thus, the present article had as its general objective to point out the Psychologist's performance in the face of crisis situations in the context of aeronautical accidents. It was a bibliographic research and a qualitative approach. It was observed that the area of aviation psychology guides its activities from prevention to the occurrence of accidents, dialoguing directly with the integral risk and disaster management proposed by the Federal Council of Psychology. In this sense, considering the occurrence of an aviation accident, the groups most affected tend to be: survivors; rescue team members and firefighters; family and friends; witnesses and crew, which can cause a crisis situation and transient or prolonged psychological impacts, which can include psychological disorders and significant changes in life. In this perspective, the crisis intervention aims to help the person affected by the search for adaptive strategies to their new situation and also in the prevention of PostTraumatic Stress Disorder. It was concluded that in order to act in crisis management after the accident, it is necessary to provide humanized support to those affected, in addition to the use of First Aid Psychological techniques throughout the first month after the disaster.

Keywords: Psychology. Aviation. Aeronautical Accidents. Disasters. Crisis Intervention.

\section{INTRODUÇÃO}

Com o crescimento da demanda de passageiros para o transporte aéreo, a segurança da aviação civil tem evoluído cada vez mais através de uma estrita regulamentação, uso de alta tecnologia e recursos humanos qualificados, visando desenvolver medidas preventivas capazes de identificar as vulnerabilidades que possam afetar o setor aéreo (ARCÚRIO, 2014). Em aviação, acidentes são considerados situações fora do comum e a prevenção se dá por meio de exclusão dos fatores que possam levar a sua ocorrência, mas é preciso entender que apesar da prevenção, acidentes aeronáuticos continuam sendo uma realidade (FAJER, 2019).

A psicologia na aviação vem pautando sua atuação desde a prevenção até as intervenções pós acidente. A prevenção de acidentes aeronáuticos levam em consideração o estudo de fatores humanos que possam acarretar em condições inseguras de voo, uma vez que o exercício de trabalho de profissionais da aviação (pilotos, tripulação, controladores de tráfego) exige lidar com protocolos, procedimentos padrão e também com situações inesperadas que demandam do profissional uma tomada de decisão em um pequeno espaço 
de tempo, visando minimizar as falhas humanas no ambiente aeronáutico (CORDEIRO; OLIVEIRA, 2019).

Essa visão integral do campo da psicologia da aviação dialoga com as orientações do Conselho Federal de Psicologia (CFP) ao considerar que situações de emergências e desastres precisam ser olhadas a partir da prevenção e até a recuperação (CFP, 2016). É nesse sentido que entra em campo a atuação do psicólogo em todo o processo de segurança de voo e estudo dos fatores humanos, a fim de contribuir para um ambiente aeronáutico o mais estável possível.

Os desastres podem ser entendidos como eventos inesperados, que são capazes de gerar grandes danos e abalos físicos e psíquicos em pessoas envolvidas. São considerados desastres humanos aqueles ocorridos por ação ou negligência do homem; dentro dos desastres humanos existem os desastres tecnológicos que advém de meios criados e manipulados pelo homem, como os meios de transportes (SILVA et al., 2013). Nesse sentido, acidentes aeronáuticos podem ser classificados como desastres tecnológicos.

De acordo com a Norma do Sistema do Comando da Aeronáutica (NSCA 3-13), que dispõe sobre o protocolo de investigação de ocorrências aeronáuticas da aviação civil conduzidas pelo estado brasileiro, o acidente aeronáutico é conceituado como:

Toda ocorrência aeronáutica relacionada à operação de uma aeronave tripulada, havida entre o momento em que uma pessoa nela embarca com a intenção de realizar um voo até o momento em que todas as pessoas tenham dela desembarcado [...], durante os quais, pelo menos uma das situações abaixo ocorra: a) uma pessoa sofra lesão grave ou venha a falecer como resultado de: estar na aeronave; ter contato direto com qualquer parte da aeronave, incluindo aquelas que dela tenham se desprendido; ou ser submetida à exposição direta do sopro de hélice, de rotor ou de escapamento de jato, ou às suas consequências [...] (BRASIL, 2017, p.9).

De acordo com Sougey (2015), entre 2006 e 2014, ocorreram quatro acidentes aeronáuticos considerados de grande porte em território brasileiro, envolvendo a aviação comercial e o transporte de passageiros. Dessa forma, uma situação de desastre exige uma infraestrutura maior para lidar com o número de vítimas e pode ser considerado um evento estressante por características como: imprevisibilidade e alto risco à integridade física e emocional das pessoas envolvidas (PARANHOS; WERLANG, 2015). 
Todas essas características levam vítimas, familiares e pessoas próximas a vivenciarem emoções intensas, ou seja, passar por um estado de crise. Entende-se por crise, uma ruptura no equilíbrio, uma mudança repentina geralmente ocasionada por um evento desencadeador. Durante esse período de desorganização psíquica, é comum o enfraquecimento das estratégias de enfrentamento do indivíduo, o que pode ocasionar a sensação de incapacidade de lidar com a situação. Dessa forma, a crise pode ser superada de forma positiva ou negativa (SÁ; WERLANG; PARANHOS, 2008).

Em uma situação de crise, as defesas do indivíduo se enfraquecem de tal forma que se encontram mais receptivos à ajuda. Nesse sentido, as intervenções podem ter resultados positivos no sentido de facilitar o processo de enfrentamento do evento traumático de uma maneira mais adaptativa, ou seja, o próprio sujeito encontra novos modos de funcionamento psicológico e social diante da nova situação, sendo imprescindível que esse tipo de assistência ocorra o mais rápido possível após o estresse (SÁ; WERLANG; PARANHOS, 2008).

Para contextualizar o histórico de intervenções psicológicas em desastres, é importante ressaltar que essa área de atuação surgiu através de investigações nas quais as pessoas poderiam manifestar de forma individual ou coletiva, alterações psicológicas decorrentes de um trauma provocado por uma situação externa (PARANHOS; WERLANG, 2015). O primeiro registro de intervenções da psicologia das emergências e desastres no Brasil ocorreu em 1987, devido ao desastre radioativo do Césio-137 em Goiás, no qual várias pessoas tiveram contato com a substância. $\mathrm{O}$ acompanhamento objetivou reduzir a ansiedade e o medo dos moradores da cidade atingida (GONÇALVES, 2019).

Esse tipo de atuação visa auxiliar o indivíduo através de uma escuta atenta do sofrimento, bem como o profissional pode atuar auxiliando as pessoas a se situarem diante das informações, levando em consideração que esses contextos implicam muitas vezes em perdas materiais e sociais (MELO; SANTOS, 20II). Ampliando esse cenário, de que forma pode se dar a atuação do psicólogo frente a situações de crise em contextos de acidentes aeronáuticos? 
O presente estudo possui como objetivo geral apontar a atuação do psicólogo frente a situações de crise em contextos de acidentes aeronáuticos. Os objetivos específicos consistem em descrever o percurso histórico da psicologia na aviação em situação pós acidente; identificar os impactos psicológicos que um acidente aeronáutico pode provocar nas pessoas envolvidas e mapear intervenções psicológicas em crise após a ocorrência do acidente aeronáutico.

O grande interesse para a realização da pesquisa surgiu a partir dissertação de mestrado de Sougey (2015), na qual foi realizado um estudo sobre o impacto tardio na saúde mental dos familiares de vítimas do Voo Noar 4896, desastre ocorrido em Recife. Ficou evidenciado no estudo, que cada pessoa possui formas singulares de lidar com o trauma e o luto, mas o impacto à saúde e as mudanças significativas nas relações e condições sociais, se mostraram presentes na maioria dos participantes da pesquisa. A pesquisadora também evidenciou a importância do atendimento pós acidente como um fator positivo para a diminuição dos impactos tardios.

Sendo assim, o estudo mostra-se relevante, pois parte em busca de um fortalecimento do campo de atuação em emergências e desastres atreladas ao contexto aeronáutico. Bem como traz o enfoque para a teoria e prática da intervenção em crise, no sentido de compreender os aspectos psicológicos do pós acidente e contextualizar as intervenções possíveis.

\section{MÉTODO}

Para a realização da pesquisa, foi escolhida a pesquisa bibliográfica, que segundo Gil (2002), consiste na utilização de material já elaborado, principalmente de livros e artigos científicos. Esse tipo de pesquisa apresenta como principal vantagem ao pesquisador a possibilidade de uma visão mais ampla dos fenômenos estudados, porém torna-se estritamente necessário analisar as informações para evitar a ampliação e reprodução de erros advindos de dados coletados de forma equivocada (GIL, 2002).

Tratou-se também, de uma pesquisa de abordagem qualitativa, que não busca empregar instrumental estatístico para análise de dados, mas procura entender os fenômenos do mundo social visualizando o contexto, e, se possível, tendo uma integração empática com 
o objeto de estudo (NEVES, 1996). O referencial teórico da pesquisa se fundamentou na Teoria da crise e intervenção em crise, que considera eventos de emergências, desastres e catástrofes como fortes desencadeadores de estresse e desorganização psíquica; com isso, busca-se auxiliar o sujeito nas condições de superação positiva do evento traumático (PARANHOS; WERLANG, 2015).

Durante o processo de busca para a revisão de literatura deste artigo, foram considerados os bancos de dados: SciElo, Biblioteca Virtual de Saúde (BVS), Biblioteca Digital Brasileira de Teses e Dissertações (BDTD) e Coordenação de Aperfeiçoamento de Pessoal de Nível Superior (CAPES). As palavras chaves em língua portuguesa foram: "Psicologia, Aviação", "Psicologia, Acidente aéreo”, "Intervenção em crise, Psicologia”, "Psicologia, emergências e desastres". A partir dos materiais analisados, também foram coletados textos científicos a partir de suas referências bibliográficas. Como terceira busca de materiais, foi encontrada uma coletânea de artigos científicos no site do Instituto de

Psicologia da Aeronáutica (IPA), bem como houve a utilização do livro "Os Voos da Psicologia no Brasil: estudos e práticas na aviação”.

Ao todo, nas pesquisas nos bancos de dados foram encontrados 298 materiais, sendo selecionados II. Somados a esses, a partir das referências bibliográficas, foram incluídos mais 3. O critério de inclusão se deu através daqueles que englobavam a atuação do psicólogo em contextos de acidentes aeronáuticos, emergência, desastres e intervenções em crise. $\mathrm{O}$ critério de exclusão se deu através de materiais que não estavam traduzidos ao português. $\mathrm{Na}$ coletânea de artigos científicos da IPA, de II artigos sobre a psicologia da aeronáutica, apenas I foi selecionado com foco nas atuações do psicólogo no pós acidente e no livro "Os voos da Psicologia no Brasil: estudos e práticas na aviação" de 12 capítulos, 3 foram selecionados seguindo o mesmo critério acima.

\section{FUNDAMENTAÇÃO TEÓRICA}

\section{I Percurso histórico da atuação de psicólogos no pós acidente}

No que tange a inserção do psicólogo na aviação, o enfoque em atendimento pós acidente é uma dentre várias possibilidades de trabalho, a saber: empresas aéreas, cursos de formação de aeronautas, órgãos reguladores da aviação, investigação de acidentes 
aeronáuticos, dentre outras atividades. No entanto, a psicologia da aviação e seus diversos campos de atuação ainda estão se consolidando no Brasil e buscando reconhecimento enquanto especialização, motivo pelo qual muitos profissionais ainda não conhecem a área (RIBEIRO, 2019).

Um órgão importante para o campo da psicologia da aviação é o Instituto de Psicologia da Aeronáutica (IPA) que vem desenvolvendo atividades em diversos âmbitos da psicologia oferecendo suporte para as Organizações Militares e ao Comando da Aeronáutica. O IPA é responsável por coordenar o Curso de Psicologia da Aviação, além de se comprometer na busca constante por aprimoramento quanto a técnicas para apoio psicológico em eventos traumáticos (IPA, [s.d]).

Em 2013, foi criada a Associação Brasileira de Psicologia da Aviação (ABRAPAV), com a finalidade de agregar psicólogos que se interessem pela psicologia aplicada à aviação, considerando a segurança e bem-estar das pessoas que estão direta ou indiretamente ligadas ao transporte aéreo. A ABRAPAV conta com um banco de dados referente a pesquisas realizadas por psicólogos a respeito de diferentes setores da aviação, além de promover atividades para constante troca de práticas profissionais (ABRAPAV, 2013). Nesse contexto, o campo da psicologia no pós acidente também é reconhecida pela associação.

A história da psicologia da aviação por muitas vezes está interligada com o surgimento da psicologia das emergências, pois desde os primórdios da atividade aérea ocorrem acidentes, sendo necessário o olhar psicológico para as situações de crise. Nesse sentido, durante a Segunda Guerra Mundial ocorreram as primeiras sessões catárticas com as Forças Armadas, o que posteriormente resultou na técnica de Debriefing Psicológico ou relato psicológico, que consistem em entrevistas realizadas entre um e três dias após o episódio traumático (CORDEIRO; OLIVEIRA, 20I9).

As contribuições brasileiras na prática do pós acidente aeronáutico tiveram como marco inicial o acidente com uma aeronave da empresa TAM, em São Paulo, no ano de 1996, ocasionando a morte de 99 pessoas entre passageiros, tripulantes e um morador das casas atingidas. Diante da emergência, um grupo de psicólogos atuou nos dias imediatos ao desastre junto a familiares das vítimas e funcionários da empresa (COGO, 20I0). 
Dois anos após essa ocorrência, um outro grupo de psicólogos preparou-se para atuar em situações futuras de desastres, trauma e luto complicado; respondendo às determinações do Departamento de Aviação Civil (DAC), sobre assistência a familiares de passageiros vítimas de acidentes aeronáuticos. Algumas características desse grupo eram de que os psicólogos tivessem disponibilidade para serem acionados a qualquer momento, disponibilidade para viajar para qualquer lugar do mundo, saber falar outro idioma além do português e ter participado dos treinamentos mensais (FRANCO, 2005).

Posteriormente, a Instrução de Aviação Civil (IAC 200-IooI), conhecida como o Plano de Assistência às Vítimas de Acidente Aeronáutico e Apoio a Seus Familiares, previu uma padronização de procedimentos a serem adotados pelas empresas aéreas e administrações aeroportuárias em caso de acidente aeronáutico. Em especial, tem-se em um dos procedimentos a serem adotados pela empresa aérea envolvida no acidente: "Provisão de acomodação, alimentação, segurança, assistência médica, psicológica e religiosa aos familiares das vítimas e sobreviventes enquanto no Centro de Assistência Familiar" (BRASIL, 2005, p.4). É nesse sentido que entra em campo o grupo de psicólogos que atuam no pós acidente.

Dessa forma, o CFP em suas atribuições legais de disciplinar e fiscalizar a atuação dos psicólogos, lançou uma nota técnica sobre a atuação da psicologia na gestão integral de riscos e de desastres, que pode ocorrer desde a prevenção até a resposta e recuperação, levando em consideração a Política Nacional de Proteção e Defesa Civil. Nesse sentido, o psicólogo com atuação em desastres baseará sua prática no Código de Ética e demais regulamentações, além de estar devidamente inscrito no Conselho Regional de Psicologia de sua área (CFP, 2016).

É sabido que acidentes aéreos não ocorrem com frequência, mas quando acontecem, afetam emocionalmente um número maior de pessoas, que podem ser: sobreviventes; membros de equipe de resgate e bombeiros; familiares e amigos; testemunhas e tripulantes (FONSECA; BARRETO, 2007). Dessa forma, é preciso levar em consideração que um acidente aeronáutico é uma situação de desastre capaz de gerar impactos psicológicos nas pessoas envolvidas direta ou indiretamente. 


\subsection{Impactos psicológicos}

Um evento traumático ocorre em condições não cotidianas e possui uma característica aflitiva para os envolvidos, especialmente quando há ocorrência de mortes súbitas, repentinas e prematuras; desaparecimento de corpos; ferimentos graves ou ameaça a continuidade da vida (D'ORIO, 2010). Nesse sentido, ao embarcar em um voo, geralmente tem-se a ideia de que aquela é uma situação rotineira e que todos chegarão bem ao local de destino, fator pelo qual um acidente aeronáutico pode representar um evento estressante capaz de mudar repentinamente o fluxo de vida.

Uma ocorrência dessa ordem pode desencadear uma experiência traumática capaz de produzir diversas consequências emocionais, cognitivas, comportamentais e somáticas, que na maioria das pessoas podem ser transitórias, mas em outras podem ser sentidas como uma vivência prolongada e intensa, que acarreta danos a sua vida profissional, familiar e social (BARRETO; FONSECA, 2010). No entanto, nem sempre a vivência traumática será totalmente negativa. Na maioria dos casos, é possível que após algumas semanas do evento estressor, as pessoas afetadas se reorganizem pessoal e profissionalmente, além de buscar uma reorientação aos seus valores e metas (FONSECA; BARRETO, 2007).

No caso de acidentes aeronáuticos, a situação inesperada pode envolver várias pessoas da mesma família e gerar o temor de que os corpos de seus entes queridos sejam danificados ou destruídos, quando não é possível realizar o resgate. Diante desse contexto é possível que esses familiares não desenvolvam mecanismos para lidar com a perda, podendo ser um fator de risco ao luto complicado ou prolongado, caracterizados como uma vivência de luto fora do dito padrão de normalidade (SOUGEY, 2015). Essa dificuldade advém de uma característica do luto por desastres, que é a ambiguidade da perda, já que em muitos casos os familiares não conseguem ao menos realizar o ritual fúnebre de seu ente querido (FRANCO, 2012). 
Pelo fato de desastres apresentarem grande repercussão nas mídias, há a possibilidade de instalação do luto público, que são manifestações de luto até mesmo por pessoas desconhecidas e sem nenhum tipo de relação significativa. Esse estado de luto público pode ter explicações culturais, políticas e psicológicas (FRANCO, 2012). Sendo importante reconhecer que um acidente aeronáutico pode apresentar impactos em toda uma comunidade.

De acordo com Ross e Menezes (2015), a ocorrência de um acidente aéreo possui alta probabilidade de instalação do Transtorno de Estresse Pós-Traumático (TEPT), que é entendido como um transtorno de ansiedade ocasionado por um evento traumático. $\mathrm{O}$ TEPT possui um conjunto de características que causam sofrimento significativo e prejuízos em diversas áreas da vida do indivíduo, sendo necessário os profissionais estarem atentos para atuarem na sua prevenção. Para Fonseca e Barreto (2007), a partir da exposição ao evento traumático, é estimado que entre 10\% e 30\% das pessoas possam ser acometidas pelo TEPT, sendo mais comum em crianças (por não possuírem mecanismos de enfrentamento) e idosos (por possuírem mecanismos de enfrentamento mais rígidos).

No Manual Diagnóstico e Estatístico dos Transtornos Mentais DSM-5, é possível encontrar uma descrição mais detalhada a respeito do TEPT. Cabe ressaltar alguns sintomas e aspectos relevantes: lembranças intrusivas e involuntárias do evento, sonhos angustiantes, sensação de estar vivendo o evento traumático novamente, alterações cognitivas e de humor, comportamento irritadiço, comportamentos autodestrutivos e perturbações do sono. Também há a possibilidade de que esses sintomas possam apresentar expressão tardia caso surjam após 6 meses do evento traumático (AMERICAN PSYCHIATRIC ASSOCIATION, 2014).

De acordo com Sougey (2015), em seu estudo sobre o impacto tardio na saúde mental de familiares de vítimas do Voo Noar 4896, há evidências de que um acidente aeronáutico é capaz de gerar adoecimento tardio nos familiares mesmo após dois anos de sua ocorrência. O que se mostrou presente na maioria dos casos: Episódio Depressivo Maior, Transtorno de Ansiedade Generalizada, Transtorno Distímico e Transtorno de Estresse Pós-Traumático como sendo as doenças mais comuns nos familiares pesquisados. 
Também é possível apontar: mudanças significativas na vida social e econômica dos familiares, possibilidade de distúrbio alimentar, luto prolongado ou complicado, sentimento de injustiça, angústia e ansiedade. No entanto, o estudo evidencia que é de suma importância em uma situação de crise receber apoio, ser escutado e contar com presença humana (SOUGEY, 2015). Nesse sentido, torna-se necessário a presença de psicólogos atuando no momento da crise após a ocorrência de um acidente aeronáutico de forma a minimizar impactos tardios.

\subsection{Intervenção em crise após ocorrência de acidente aeronáutico}

De acordo com Pereira (2019) um dos maiores desafios para atendimentos em situações de crise após acidente aeronáutico, é que muitos profissionais não conseguem desprender-se de aprendizados teóricos, quando tudo o que se pode fazer no momento é oferecer um copo de água e a própria companhia para que os sentimentos da pessoa possam fluir livremente. Nesse sentido, o profissional precisa ser flexível e atuar no aqui e agora.

O psicólogo também deve estar presente durante todo o protocolo do atendimento, especialmente no gerenciamento de crise, quando há identificação e liberação dos corpos. Nesse momento ele irá oferecer suporte identificando vulnerabilidades que podem se intensificar nas pessoas enlutadas, auxiliando-as no desenvolvimento de expectativas de futuro. Dessa forma, o psicólogo atua como facilitador, partindo do pressuposto que não deve fazer tudo, mas os assistidos devem buscar os próprios caminhos para seguir em frente (PEREIRA, 2019).

Um outro ponto relevante é o autocuidado da equipe que presta assistência na situação de crise "A equipe de atendimento deve estar sempre se trabalhando, buscando apoiar um ao outro e se permitindo sair, por alguns momentos, do local onde o grupo de familiares, funcionários e outros são atendidos, para oxigenar sua condição psicológica.” (PEREIRA, 2019, p. 186). Nesse sentido, a autora considera que certos intervalos são necessários para que o profissional não se sinta sobrecarregado, e, dessa forma, preste uma melhor assistência.

De acordo com Franco (2012), a intervenção em crise objetiva a resolução de questões que exercem maior pressão no indivíduo através de uma intervenção focalizada, a 
fim de que o cliente possa encontrar novas maneiras adaptativas para lidar com sua realidade. Bem como nos casos em que há perdas, o profissional precisa compreender o que mudou na vida do indivíduo e auxiliá-lo no processo de construção de um novo significado.

De acordo com Silva et al. (2013), as intervenções realizadas durante o primeiro mês após o evento traumático objetivam a prevenção de reações desadaptativas a longo prazo. Os autores citam uma forma de intervenção denominada como Primeiros Socorros Psicológicos (PSP), que consiste em protocolos de intervenção com o objetivo de tornar padrão o atendimento aos afetados em reações agudas ao estresse.

Os PSP possuem nove etapas: primeira: preparação (pensar em estratégias para a população afetada); segunda: primeiros contatos (se apresentar para as vítimas e auxiliar no atendimento de suas necessidades básicas); terceira: segurança e conforto (acompanhar no reconhecimento dos corpos, auxiliar nas questões de luto); quarta: estabilização (orientar as vítimas mais vulneráveis emocionalmente a um acompanhamento profissional continuado), quinta: busca de informações (investigar com cuidado o histórico de traumas anteriores, saúde física e psicológica); sexta: assistência prática (auxiliar na busca de serviços de saúde, dar assistência quanto a documentos necessários); sétima: contato com o apoio social (auxiliar no mapeamento de redes de apoio como familiares, instituições espirituais); oitava: estratégias de manejo (informar sobre reações comuns ao estresse e procurar técnicas de enfrentamento); nona: contato com serviços de colaboração (manter contato com os serviços de referência) (SILVA et al., 2013).

Uma outra técnica utilizada para a prevenção do TEPT e que possui resultados positivos em contextos de acidentes aeronáuticos é o Critical Incident Stress Debriefing (CISD), no qual parte do pressuposto que as consequências de um evento traumático podem ser minimizadas através do relato da situação. O CISD é realizado em grupo e possui as seguintes etapas: primeira: introdução (explicação de objetivos); segunda: fato (narrativa dos fatos); terceira: pensamento (descrição das reações cognitivas); quarta: reações emocionais (expressão das reações emocionais); quinta: informação (informações sobre estratégias para lidar com o estresse) e sexta: re-entrada (fechamento) (BARRETO; FONSECA, 2010). 
Ao finalizar sua atuação, o psicólogo deverá comunicar quando necessário, possibilidades de continuidade do trabalho e encaminhamento dos casos. Nesse sentido, torna-se imprescindível que o profissional esteja vinculado às políticas públicas e buscando o constante fortalecimento do Sistema Único de Saúde (SUS), pois é nesse âmbito que são desenvolvidas as estratégias de saúde mental e de atenção psicossocial como forma de garantir o acesso às ações e serviços de saúde para a população afetada por desastres (CFP, 2016). Nessa perspectiva, é possível pensar desde o processo inicial junto à situação crítica, bem como na continuidade desse cuidado a partir das redes específicas de saúde dos territórios. É com base nesse olhar que se pode construir uma gestão integral de riscos e desastres, a fim de prestar uma assistência efetiva e humanizada às pessoas afetadas por acidentes aeronáuticos.

\section{${ }_{4}$ CONSIDERAÇÕES FINAIS}

Este estudo possibilitou um maior entendimento acerca da atuação do psicólogo na aviação, área ainda considerada desconhecida por muitos profissionais e estudantes de psicologia. O contexto histórico nos levou a entender o que tem sido feito para o constante aprimoramento da psicologia da aviação em situações de crise após ocorrência de acidente aeronáutico através de órgãos como o IPA e a ABRAPAV, bem como através de estudos sobre intervenções em crise.

Também é importante citar os avanços das normatizações quanto aos procedimentos a serem adotados em casos de acidentes aeronáuticos, através do plano de assistência às vítimas de acidente aeronáutico e apoio a seus familiares, que incluem o psicólogo como figura essencial no processo de assistência e gerenciamento de crise; bem como as normatizações do CFP através da nota técnica sobre a atuação da psicologia na gestão integral de riscos e de desastres. Ao falar em acidentes aeronáuticos, mostrou-se necessário levar em consideração que este pode ser entendido como um evento estressante e inesperado, que ocasiona uma situação de crise nas pessoas envolvidas, já que muda repentinamente o fluxo de vida.

O estudo apontou que dentre os impactos psicológicos após um acidente aéreo, está o prolongamento da vivência traumática que pode ocasionar danos à vida profissional e 
social do indivíduo; experiência de luto traumático ou prolongado; aparecimento de transtornos psicológicos como Episódio Depressivo Maior, Transtorno de Ansiedade Generalizada, TEPT, além de outros impactos tardios. Nesse sentido, tornou-se relevante abordar a importância dos profissionais de psicologia em situações como essas, a fim de prestar o devido suporte e minimizar tais impactos.

Para isso, evidenciou-se a necessidade de flexibilidade do profissional, pois no momento da crise atuar no aqui e agora prestando suporte os assistidos é tudo que pode ser feito na maioria das vezes. Por isso, é imprescindível que o psicólogo também olhe para si e faça pausas ao longo do processo. Além disso, o psicólogo deve pautar sua atuação como facilitador, mas nunca tomando as rédeas da situação: seu papel é o de auxiliar os assistidos no desenvolvimento de expectativas de futuro através de intervenções focalizadas, compreendendo as mudanças acontecidas na vida do sujeito.

Além disso, o estudo pontuou intervenções que podem ser realizadas durante os primeiros dias e meses após a ocorrência do acidente, visando a diminuição de reações desadaptativas a longo prazo: os PSP, que possuem nove etapas e o CISD, que possui seis etapas. Ambas as técnicas se mostraram eficazes para a prevenção do TEPT. Para o processo de recuperação daqueles que necessitarem de encaminhamentos, evidenciou-se a importância do psicólogo estar dialogando com as políticas públicas, pois é nesse âmbito que são pensadas estratégias de continuidade do cuidado, a partir da rede assistencial do SUS.

Nesse sentido, o estudo levou em consideração a importância da atuação do psicólogo desde a prevenção de acidentes aeronáuticos até a sua ocorrência, visando intervenções frente ao sujeito em situação de crise. Tendo em vista que essa é uma área em desenvolvimento, torna-se essencial o surgimento de novas pesquisas a fim de olhar para o ambiente aeronáutico de uma forma integrada e que leve em consideração os fatores preventivos e assistenciais de acidentes, a fim de contribuir para uma aviação mais segura e para uma prática de intervenção em crise humanizada, pois essa também é a responsabilidade social do psicólogo inserido na aviação.

\section{REFERÊNCIAS}


ABRAPAV.Sobre. Rio de Janeiro. c2013. Disponível em: 〈https://www.abrapav.com.br/about2〉. Acesso em: 07 nov. 2020.

AMERICAN PSYCHIATRIC ASSOCIATION. Manual diagnóstico e estatístico de transtornos mentais. Tradução de M. I. C. Nascimento. 5. ed. Porto Alegre: Artmed, 2014.

ARCÚRIO, Michelle Salgado Ferreira. Impactos dos fatores e erros humanos no processo de inspeção de segurança da aviação civil brasileira. 2014. 318 f. Dissertação (Mestrado) Curso de Transportes, Engenharia Civil e Ambiental. Unb, Brasília, 20r4. Disponível em: 〈https://repositorio.unb.br/handle/ro482/r7201>. Acesso em: 09 jun. 2020.

BARRETO, Márcia Regina Molinari; FÔNSECA, Cintia Saba. Suporte psicológico após ocorrência de acidente aeronáutico: relato de uma experiência. Conexão SIPAER, Brasília, v. I, n. 3, p. 195-206, jul. 2010. Disponível em: $\langle$ http://conexaosipaer.cenipa.gov.br/index.php/sipaer/article/download/49/85>. Acesso em: 09 abr. 2020.

BRASIL, Comando da Aeronáutica, Departamento de Aviação Civil, Subdepartamento de Serviços Aéreos, Divisão de Fiscalização, IAC 200-ıooı, Plano de Assistência às vítimas de acidente aeronáutico $e$ apoio a seus familiares. 2005. Disponível em: <https://www.anac.gov.br/assuntos/legislacao/legislacao-I/iac-e-is/iac/iac-20oIoor/@@display-file/arquivo_norma/IAC20o_roor.pdf >. Acesso em: Io jun. 2020.

BRASIL, Ministério da Defesa, Comando da Aeronáutica, NSCA 3-13. Protocolos de Investigação de Ocorrências Aeronáuticas da Aviação Civil Conduzidas Pelo Estado Brasileiro, 2017. Disponível em:< https://www2.fab.mil.br/cenipa/index.php/legislacao/nsca-norma-do-sistema-docomando-da-aeronautica?download=II2:nsca3-13>. Acesso em: 28 abr. 2020

CFP. Nota técnica sobre atuação da psicologia na gestão integral de riscos e de desastres, relacionadas com a política de proteção e defesa civil. Brasília, 20I6. Disponível em: 〈https://site.cfp.org.br/documentos/nota-tecnica-sobre-atuacao-da-psicologia-na-gestaointegral-de-riscos-e-de-desastres-relacionadas-com-a-politica-de-protecao-e-defesa-civil/>. Acesso em 07 nov. 2020 .

COGO, Adriana Silveira. $O$ psicólogo com atuação em emergências: experiência e significado. 2010. I32 f. Dissertação (Mestrado) - Curso de Psicologia Clínica, Pontifícia Universidade Católica de São Paulo, São Paulo, 2oro. Disponível em: 〈https://tede2.pucsp.br/handle/handle/15935> Acesso em: 3 abr. 2020.

CORDEIRO, Daniela de Carvalho; OLIVEIRA, Juliana Guimarães de. Relato de experiência de suporte psicológico pós-acidente aeronáutico em aviação de caça. Conexão SIPAER, Brasília, Vol. Io, Nº. 2, pp. 6-14, 2019. 
D'ORIO, Rosana Teresinha. Histórias de fins, histórias sem fins... um estudo sobre rituais no processo de luto. 205f. Tese (Doutorado) - Curso de Psicologia Clínica, Pontifícia Universidade Católica de São Paulo, São Paulo, 2oro. Disponível em: 〈https://sapientia.pucsp.br/handle/handle/15939〉. Acesso em 07. nov. 2020.

FAJER, Márcia. O olhar do psicólogo na investigação de acidentes aeronáuticos. In: SANTOS, Cesar da Silva; Et al. Os voos da psicologia no Brasil: estudos e práticas na aviação. Pod Editora, Rio de janeiro, 2019, pp. 213-240.

FÔNSECA, Cintia Saba; BARRETO, Márcia Regina Molinari. Aspectos Psicológicos no Pós-Acidente. In: BORGES, Janete de Paiva; Et al. Coletânea de Artigos Científicos. Ed. Comemorativa. Rio de Janeiro, 2007. p. 37-47.

FRANCO, Maria Helena Pereira. Atendimento psicológico para emergências em aviação: a teoria revista na prática. Estudos de psicologia, Natal, v. Io, n. 2, p. 177-180, ago. 2005. Disponível em: <http://www.scielo.br/scielo.php?script=sci_arttext\&pid=SI4I3294X2005000200003\&lng=en\&nrm=iso $>$. Acesso em: 03 abr. 2020.

FRANCO, Maria Helena Pereira. Crises e desastres: a resposta psicológica diante do luto. O Mundo da Saúde, São Paulo, Vol. 36, №. I: p. 54-58, 2012. Disponível em: 〈https://pesquisa.bvsalud.org/portal/resource/pt/mis-36664〉 Acesso em: 20. nov. 2020. GIL, Antônio Carlos. Que é pesquisa bibliográfica? In: GIL, Antônio Carlos. Como elaborarrojetos de pesquisa. 4. Ed. São Paulo: Editora Atlas, 2002. p. 44-45.

ONÇALVES, Rita Santos Portela. O trabalho do psicólogo em situações de emergências e desastres. 2019. 40 f. TCC (Graduação) - Curso de Psicologia, Universidade Regional do Noroeste do Estado e do Rio Grande do Sul, Ijuí, 2019. Disponível em: 〈http://bibliodigital.unijui.edu.br:808o/xmlui/handle/123456789/6573〉. Acesso em: 8 mai. 2020.

IPA, Força Aérea Brasileira. Histórico. Rio de Janeiro. [s.d.]. Disponível em: 〈https://www2.fab.mil.br/ipa/index.php/historico/2-uncategorised/171-historico〉. Acesso em: 07 nov. 2020 .

MELO, Cecília Araújo; SANTOS, Felipe Almeida dos. As contribuições da psicologia nas emergências e desastres. Psicólogo inFormação, São Paulo, v. 15, n. 15, p. I69-18I, 2011. Disponível em: <http://pepsic.bvsalud.org/scielo.php?script=sci_arttext\&pid=SI4I58809201100orooor2> Acesso em: 03 abr. 2020.

NEVES, José Luis. Pesquisa qualitativa: características, usos e possibilidades. Cadernos de pesquisas em administração, São Paulo, v. I, n. 3, p. I-5, 1996. Disponível em: 〈http://www.hugoribeiro.com.br/biblioteca-digital/NEVES-Pesquisa_Qualitativa.pdf〉. Acesso em: 9 abr. 2020. 
PARANHOS, Mariana Esteves; WERLANG, Blanca Susana Guevara. Psicologia nas Emergências: uma Nova Prática a Ser Discutida. Psicologia: ciência e profissão, Brasília, v. 35, n. 2, p. 557-571, jun. 2015. Disponível em: $<$ http://www.scielo.br/scielo.php?script=sci_arttext\&pid=SI4I498932015000200557\&lng=en\&nrm=iso >. Acesso em: 22 mar. 2020.

PEREIRA, Maria da Conceição Correia. Intervenção em crise: Relato de um atendimento psicológico no contexto de um acidente aeronáutico: O voo 1907. In: SANTOS, Cesar da Silva; Et al. Os voos da psicologia no Brasil: estudos e práticas na aviação. Pod Editora, Rio de janeiro, 2019, p. 173-188.

RIBEIRO, Selma Leal de Oliveira. Breve retrospectiva histórica sobre a participação da psicologia no contexto da aviação. In: SANTOS, Cesar da Silva et al. Os voos da psicologia no Brasil: estudos e práticas na aviação. Pod Editora, Rio de janeiro, 2019, p. 21-50.

ROOS, Danielle; MENEZES, Tamara. Desastres aéreos e intervenções psicológicas: prevenção do transtorno de estresse pós-traumático. Conexão SIPAER, Brasília, Vol. 6, No. I, p 6r-64, abr. 2015.

SÁ, Samantha Dubugras; WERLANG, Blanca Susana Guevara; PARANHOS, Mariana Esteves. Intervenção em crise. Revista brasileira de terapias cognitivas, Rio de Janeiro, v. 4 , n. I, jun. 2008. Disponível em <http://pepsic.bvsalud.org/scielo.php?script=sci_arttext\&pid=SI8o8$56872008000100008 \& \operatorname{lng}=\mathrm{pt} \& \mathrm{nrm}=$ iso $>$. Acesso em: Io mai. 2020 .

SILVA, Thiago Loreto Garcia et al. Revista Brasileira de Psicoterapia, Porto Alegre, v. I, n. 15, p. 93-104, 2013. Disponível em: <https://pesquisa.bvsalud.org/portal/resource/pt/biblio847662> Acesso em: 20. Nov. 2020.

SOUGEY, Maria da Conceição Pereira. Impacto tardio na saúde mental nos familiares de vítimas de Acidente Aeronáutico: o caso Noar Voo 4896. 2015. 130 f. Tese (Doutorado) Curso de Neuropsiquiatria e Ciências do Comportamento, Centro de Ciências da Saúde, Universidade Federal de Pernambuco, Recife, 2015. Disponível em: 〈https://repositorio.ufpe.br/handle/123456789/16931〉. Acesso em: 03 abr. 2020. 
